\title{
Reactividad de la vía aérea en la bronquitis obstructiva recidivante
}

\author{
Drs. Ramiro Gonzâlez V., ${ }^{1}$ Guido Girardi B., ${ }^{2}$ Sr. Ricardo Muñoz ${ }^{3}$
}

\author{
Airway reaclivity in recurrent obstructive bronchitis
}

\begin{abstract}
Fortytwo apparently asymptomutic children who had history of securrent wheezing betore the age ut 2 years, were evaluated for subsequent respiratury symptons and airway hiperreactivity, between 4 and 7 years of age. 20 children had milil episodes ot wheezy bronchitis and 20.9 ot theers asymptomatics, had inc reased bronchial lability when they were challenged with Exercise Test. These children and demanstated asthniatic patient: have similar incidences of positive Exercise Test and lacnily history of Asthma, which sotggest; that both groups must le considered members of a same population with a common basic genetic deficiency.
\end{abstract}

Là relación entre bronguitis obstructiva retidivante (BOR) y asma bronquial ha sido objeto de múltiples estudios y controversias. El seguimiento de los lactantes con BOR ha permitido establecer que, en la edad escolar, la mitad de ellos tiene asma clínicamente evidente. ${ }^{1}$ En estos casos es lógico suponer que la enfermedad inició sus manifestaciones con episodios broncuuiales obstructivos durante la lactancia.

El hecho, sobre el cual existe consenso, de que la BOR es una enfermedad que tiende a mejorar hacia los dos años de edad ha contribuido a considerarla cono un cuadro antolimitado en el tiempo; sin embargo, existen estudios epidemiológicos en los que no se la ha podido separar como una entidad distinta del asma, demostrando para ambas una misma base genética. ${ }^{2}$ Por otra parte, priebas funcionales respiratorias, practicadas a niños que aparentemente han mejorado de su $B O R$, han revelado una reactividad anormal de la vía aérea frente a las pnebas de provocación," hecho comúnmente encontrado en el asma y que

\footnotetext{
1 Médico Servicio de Pediatria Hospital Exequiel Conzález Cortés.

8 Mérlico Pediatra, Depto. de Pediatría y Cingia Intantil Sur, División Ciencias Médicas Sur, Facultad de Medicina, Universjdud de Chile.

${ }^{3}$ Kinesiologo Servicio de Pediatra-Kinesiologia Hospital Exequiel González Cortés.
}

Se acepta universalmente como criterio diagnóstico de esta enfermedad. Estas evidencias arrojan dudas sobre la opinión que se tenía de la BOR, considerándola como una patología transitoria del lactante, planteando la necesidad de nuevas investigaciones al respecto.

El propósito de este trabajo es estudiar a un grupo de estos niños con BOR, cuyas inolestias mejoraron después de los dos años de vida, a fin de establecer cuál es su condición clinica en la edad escolar, si su reactividad bronquial es anormal y si en este aspecto y en su historia familiar son comparables a un grupo de pacientes con asma comprobada.

\section{MATERLALES Y METODOS}

Se incluyó en el trabajo a $\mathbf{4 2}$ niños que presentaron BOR en sus primeros veinticuatro meses de existencia y luego de esa edad no tuvieron problemas respiratorios que los obligasen a concurrir nuevamente a nuestro Servicio.

A todos ellos se les tomó una historia clínica actual, indagando acerca de la presencia de "bronquitis con sibilancias" y su periodicidad. También se revisaron los antecedentes consignados en las historias clínicas confeccionadas en el Servicio durante la época en que fueron controlados por sus cuadros bronquiales. En base a la frecuencia de las bronquitis obstructivas en sus primeros 
2 años de vida, los pacientes se clasificaron en cuatro grados de severidad, para establecer si ésta intluía en la evaluación posterior y en el resultado de la prueba de ejercicio. Seconsideró como leves a aquellos sujetos que presentaron de tres a cuatro crisis por año; moderados a los que tuvieron entre cinco y doce de estos episodios en el mismo periodo; avanzados a los con más de doce crisis, y severos a los que tuvieron molestias pennanentes.

Otros datos considerados en investigación tueron la historia familiar de asıua y rinitis y los resultados de los exámenes practicados para estudio de la BOR: hemograma, recuento de eosinófilos en secreción nasal y bronquial, estudio de retlujo gastroesofágíco y radiografía de tórax.

Todos los individuos fueron sometidos a prueba de ejercicio, según un métudo generalmente aceptado, midiéndoseles tlujo espiratorio maximo. La muestra se dividió en dos, según su respuesta a la prueba: subgrupo (+) y subgrupo (-), según si ella provocó o no obstrucción bronquial, los que fieron comparados en base a sus antecedentes personales, tamiliares y síntonsas actuales, a fin de explicar el distinto comportamiento trente al estuerzo. Por último se analizó la incidencia de hiperreactividad y de antecedentes familiares de asma y rinitis entse estos pacientes con respecto a los encontrados en sujetos asmáticos comprobados.

\section{RESULTADO}

Lat edad promedio de los niños estudiados fue de cinco años seis meses (Tabla 1). En ella también está resumida la condición clinica de los pacientes al momento de este estudio. Del total de nin̄os, veintidós $(52 \%)$ llevaban más de dos años asintomáticos; diecisiete $(40 \%)$ tenían menos de culatro episodios de "bronquitis con sibilancias" por año, y sólo tres $(8 \%)$ tenian entre cuatrn y seis crisis anuales. En todos los casos en que aún existian síntomas, éstos fueron de intensidad leve, de corta duración y de resolución espontánea, lo que indujo a los padres a no considerar necesaria una consulta médica. La prueba de ejercicio resultó positiva en 20 niños ( $48 \%$ ), como se aprecia en la Tabla 2. Al comparar la condición clinica actual de los sujetos, a fin de explicarnos las diferencias en el resultado de la prueba, encontramos que, siendo algo mayor el número de sujetos asintomáticos en el subgrupo con prueba
(-), esta diferencia no alcanzó a ser estadísticamente significativa. Ambos sulggrupos tampoco fueron esencialmente distintos, en cuanto a la frecuencia con que sus integrantes sirtomáticos presentaban "bronquitis con silyilancias". El promedio de edad fie dle un año nayor para el subgrupo en el cue la prueba fue negativa.

\section{Tabla 1}

Edad promedio de los niños estudiados y su estado clíricos al morrtento del estudio.

Edad promedio: 5,5 años

$\begin{array}{lrl}\text { Asintonutiticos unás de } 2 \text { años } & 22 & (52 \%) \\ \text { Metoos de } 4 \text { episodios por añon } & 17 & (40 \%) \\ \text { Más de } 4 \text { episodios por año } & 3 & (8 \%)\end{array}$

Tabla 2

Resultadi) de la pneelsa de ejercicio, los sintomas presentes en el nomento del extudio, los integrantes de cada subgrupo (Test + y Test -) y su promedio de edial.

$\begin{array}{rrrr}\text { Test }(+) \text { N. } & \% & \text { Test }(-) \mathrm{N}^{0} & \not \% \\ 20 & 48 & 22 & 52\end{array}$

Extado aetual

Asintomáticos

$<4$ crisis por año

$>4$ crisis por año

Edad promedio

$\begin{array}{rrrr}9 & 45 & 13 & 59 \\ 9 & 45 & 8 & 36 \\ 2 & 10 & 1 & 5 \\ 5,17 \text { añ } & 6,08 \text { años }\end{array}$

En la Tabla 3 se aprecia que, en ambos subgrupos, las molestias de la BOR se iniciaron antes del año de vida en $95 \%$ de los casos. También se demuestra que la distribución de los niños en los distintos grados de severidad de la BOR es similar para ambos subgrupos.

El análisis hecho en la Tabla 4 revela que los antecedentes familiares de asma y rinitis son también semejantes para ambos subgrupos y que el antecedente de alergia es más frecuente entre los niños en los que la prueba de ejercicio resultó negativa. Tampoco existen diferencias significativas en los antecedentes personales de alergia ni en la eosinofilia en la sangre. La eosinofilia en secreciones fue más frecuente entre los niños con prueba (-) y el reflujo gastroesofágico entre los rniños con prueba $(+)$. 
Tabla 3

Edad de inicio de la BOR en ambos subgrupos y distribución de la severidad de sus síntomas en los primeros dos años de vida.

\begin{tabular}{lrrrr}
\hline & \multicolumn{3}{c}{ Test $(+)$} & \multicolumn{3}{c}{ Test $(-)$} \\
& N..ं & $\%$ & N.* & $\%$ \\
Inicio antes del & 19 & 95 & 21 & 95 \\
año de vida & & & & \\
& & & & \\
Frectencia de las crisis & 2 & 10 & 1 & 5 \\
< de 4 por año & 7 & 35 & 10 & 45 \\
$4-12$ por año & 8 & 40 & 10 & 45 \\
$>12$ por año & 3 & 15 & 1 & 5 \\
Permanente & & & & \\
Severidad de las crisis & & & & \\
Leves & 5 & 25 & 7 & 32 \\
Medianas & 9 & 45 & 10 & 45 \\
Severas & 6 & 30 & 5 & 23 \\
\hline
\end{tabular}

Tabla 4

Antccedentes lamiliares de asma, rinitis y alergia para ambos subgrupos. Antecedentes personales de atopia. Resultado de los exámenes de laboratorio.

\begin{tabular}{|c|c|c|c|c|}
\hline & \multicolumn{2}{|c|}{ Test (+) } & \multicolumn{2}{|c|}{ Test $(-)$} \\
\hline & N.o & $\%$ & N." & $\%$ \\
\hline \multicolumn{5}{|l|}{ Antec familiares } \\
\hline Asmay rinitis & 13 & 68 & 13 & 59 \\
\hline Alergia & 7 & 37 & 12 & 55 \\
\hline \multicolumn{5}{|l|}{ Antec personales } \\
\hline Alergia & 8 & 42 & 7 & 32 \\
\hline Eosinofilia en hemograma & 8 & 42 & 11 & 50 \\
\hline Eosingtilia en secreciones & 2 & 10 & 5 & 23 \\
\hline Reflujo gastroesolágico & 16 & 80 & 15 & 68 \\
\hline
\end{tabular}

El antecedente familiar de asma y rinitis para el total de sujetos estudiados estuvo presente en $62 \%$ de los casos ( 26 de 42 ).

\section{DISCUSION}

De los resultados obtenidos en este seguimiento se desprende que casi la mitad de los niños que aparentan mejorar de la BOR continúan presentando molestias hasta la edad escolar. El hecho de que los síntomas sean mínimos aleja a estos pacientes de los controles médicos, ya que no llaman la atención a los padres, dejando en ellos la impresión de un probleina superado. Esta situa- ción también podría explicar que nueve niños, aparentemente asintomáticos, hayan presentado hiperreactividad bronguial frente al ejercicio, que, según Godfrey, ${ }^{5}$ es un sensible indicador de "actividad" del asma y es negativa en un individuo realmente libre de toda molestia.

El distinto comportamiento frente a la prueba de esfuerzo no puede ser explicado por los antecedentes ni por diferencias en el estado clínico actual, ya que para ambas situaciones los dos subgrupos resultaron ser bastante similares. La diferencia de edad podría dar una razón al respecto, ya que se ha demostrado que luego de largos periodos asintomáticos la reactividad bronquial puede atenuarse. ${ }^{6}$

En estudios hechos en nuestros pacientes con asma bronquial comprobada, hemos encontrado que alrededor del $60 \%$ tienen antecedentes familiares de asma y/o rinitis y que la mitad presenta reactividad bronquial exagerada frente al ejercicio. $\mathrm{Katan}^{4}$ ha obtenido un $43 \%$ de positividad para la prueba de ejercicio entre asmáticos con función pulmonar norrnal de reposo. Estos resultados son prácticamente iguales a los obtenidos por nosotros en estos niños con antecedentes de BOR. Estas evidencias permiten sugerir que los lactantes con bronquitis obstructiva recidivante son en realidad asmáticos y concuerdan con opiniones recientes de distintos autores, acerca de que todo paciente con más de tres episodios de "bronquitis con sibilancias" debe ser considerado como portador de esta enfermedad una vez descartadas otras causas específicas de disnea sibilante. ${ }^{8,9}$ BOR, enfermedad bronquial obstnctiva crónica y otros nombres utilizados para designar a estos pacientes, sólo constituyen eufemismos que retardan el inicio de una terapia preventiva adecuada y oportuna.

De los datos presentados en este seguimiento, también resulta evidente que los niños con BOR nejoran notablemente su condición hacia los dos años de vida. Esto resulta perfectamente explicable por el cambio producido en las caracteristicas anatomofuncionales de la vía aérea del lactante que tavorecían la obstrucción, y por la adquisición de una madurez inmunológica que hace a los ninos mayores menos susceptibles a las infecciones virales, en especial al virus Sincicial Respiratorio, principal desencadenante de las crisis obstructivas a esta edad. ${ }^{\prime \prime}$ Sin embargo, estos pacientes siguen siendo portadores de hiperreactividad bronquial condicionada genéticamente, que si 
bien se atenúa, puede reactivarse con el estímulo apropiado, de modo que inuchos de ellos podrán recaer más tarde. Dichas recaídas pueden ocurrir después de largos períodos sin molestias y en edades en que los pacientes ya no están bajo control pediatrico, como lo ha demostrado Blair en su seguimiento a largo plazo. La condición de portadores de reactividad anormal de la vía aérea hace a estos pacientes más susceptibles a ciertos elementos nocivos como el tabaquismo, existiendo evidencias de que la función pulmonar se deteriora más rápidamente entre fumadores con antecedentes de problemas bronquiales en la infancia. ${ }^{2}$ Elto plantea la necesidad de hacer labor preventiva entre estos niños con resspecto al hábito de furmar, siendo aconsejable evitar, dentro de lo posible, la exposición a ambientes contaminados y fomentar la lactancia materna, pues ésta confiere protección contra la infección por virus Sincicial Respiratorio ${ }^{12}$ y mejora el pronóstico a largo plazo del asma."

En conclusión, pensamos que la mayoría de los lactantes con bronquitis obstructiva recidivante son asmáticos. En algunos casos la enfermedad se va atenuando, pero persiste una hiperreactividad bronguial que los hace susceptibles de reactivaciones de los síntomas. Considerada la afección de este modo, las necesidades de terapia preventiva para el control del asma y otras medidas que ya se han expresado surgen como imperativas.

\section{RESUMEV}

Se estudian 42 niños con antecedentes de haber tenido BOR en sus primeros dos años de vida, mejorando luego en apariencia. Se demuestra que entre los cinco y seis años de edad, un $48 \%$ de ellos aún presentan episodios bronquiales obstructivos leves y que un $\mathbf{4 8 \%}$ de estos pacientes tienen hiperreactividad broncuial, evidenciable con la prueba de ejercicio. El porcentaje de pruebas positivas encontrado entre estos sujetos y la frecuencia con la que presentan antecedentes familiares positivos para asma y rinitis son sinilares a las encontradas entre pacientes asmáticos. Estos hechos sugieren que los lactantes con bronquitis obstrnctiva recidivante son en realidad asmáticos $y$ que deben recibir tratamiento como tales.

\section{HEFEHENCIAS}

1 Buffum. Prognosis of Asthma in Childhood. Am. ]. Dis. Child. 112: 2 14-217, 1966.

2 Sibbald, \$, et al. A timily study of genetic basis of asthina and wheezy bronchilis. Areh. Child, 55: 354, 1940.

3 Beckerman, L. Prospective study of lung function in young children following emoup and bronchjolitis. Ped, Res. 12: 558, 1978.

4 Kattan, $M$.Response to exercise in nomial and asthmatic children. J. Pediatr. 92: 7 18, 1978.

5 Balfour-Lynn, L-: Codfrey, $S$. Relationship of exercise induced astloma to clinical asthma in childhood. Arch. Dis. Child. 56: 450, 1981.

6. Homer, A. B. Bronchial hiperreactivity. Am. Hev. Hesp. Dis. 121: 389,1980 .

7 Tabacknik, E., et al. Infantil brotuchiol asthria. J. Allergy Cl. Imrn. 67: 334, 1981.

$\$$ American Academy of Pediatric. Management of asthma. Pediatrics. Vol. 68, N. ${ }^{\circ}$, p. 874, 1981.

9 Minor T. H., et al. Viruses as precipitants of asthunatic attacks in children. J.A.M.A. 227: 292, 1974.

10) Blair, H. Natural History of Childhood Asthına. Arch. Dis. Child. 52: 613, 1977.

11 Breese Hall, C., et al. Respiratory Symcitial virus infections within Families. The N. Engl. J. Med. 294; $414,1976$. 